\title{
The Stability of Interbank Market Network: A Perspective on Contagion and Risk Sharing
}

\author{
Chi Xie, ${ }^{1,2}$ Yang Liu, ${ }^{1}$ Gang-Jin Wang, ${ }^{1,2,3}$ and Yan $\mathrm{Xu}{ }^{1,2}$ \\ ${ }^{1}$ College of Business Administration, Hunan University, Changsha 410082, China \\ ${ }^{2}$ Center of Finance and Investment Management, Hunan University, Changsha 410082, China \\ ${ }^{3}$ Center for Polymer Studies and Department of Physics, Boston University, Boston, MA 02215, USA
}

Correspondence should be addressed to Chi Xie; xiechi@hnu.edu.cn

Received 16 October 2015; Accepted 24 January 2016

Academic Editor: Kiseop Lee

Copyright (c) 2016 Chi Xie et al. This is an open access article distributed under the Creative Commons Attribution License, which permits unrestricted use, distribution, and reproduction in any medium, provided the original work is properly cited.

\begin{abstract}
As an important part of the financial system, interbank market provides banks with liquidity and credit lending and also is the main channel for risk contagion. In this paper, we test the existence of systematic risk contagion within the Chinese interbank market. By building the networks of the Chinese interbank market for each year and using the measure of mutual information, we quantitatively detect the changes of interbank market networks and observe that the correlations between banks become increasingly tighter in recent years. With the bilateral risk exposure among Chinese listed commercial banks, we find that the possibility of systemic risk contagion in Chinese interbank market is fairly small. But of great concern on each individual bank, the matter is different. Our simulation shows that the failures of three special banks (i.e., Agricultural Bank of China and Bank of China and Industrial and Commercial Bank of China) most likely lead to systemic risk contagion. Furthermore, we test the antirisk ability of the Chinese interbank market from the perspective of risk sharing and discover that the interbank market is stable when the loss scale is lower than forty percent of banks' total core capital.
\end{abstract}

\section{Introduction}

Interbank market plays a prominent role in the situation that the globalized financial activities promote the economic development. And the stability of the interbank market guarantees the health and sustainability of the economy. Interbank lending connects banks as a network and easily triggers systemic risks in the interbank market. A huge amount of relevant research shows that the failure of one bank will triggers a chain reaction causing other banks to fail through interbank lending. For example, a small liquidity preference shock in one bank can spread by contagion through the interbank lending [1] and the breakdown of a single bank can lead to risk contagion in a banking system [2].

In this paper, we test the existence of systematic risk contagion within the Chinese interbank market and the antirisk ability of the Chinese interbank market from the perspective of risk sharing. Unfortunately, we cannot observe how the actual structure of bilateral exposures affects the danger of contagion because banks do not have to disclose their counterparts [2]. But a single bank's interbank annual loans and deposits are available. Yet, on the basis of interbank lending, it is difficult to conduct an effective method to evaluate risk contagion effects between banks. Therefore, we measure the interbank exposure matrix by using maximizing entropy method and construct network of the Chinese interbank market. We also introduce a measure of mutual information to observe the changes of interbank market networks in a quantitative way. Then we estimate the possibility of risk contagion in the Chinese interbank market and analyze the ability to insure against risks from the perspective of risk sharing.

The remainder of this paper is organized as follows. Section 2 reviews the literature on financial contagion and risk sharing on the interbank market. Section 3 constructs the network of Chinese interbank market. Section 4 uses mutual information to observe the changes of interbank market networks in a quantitative way and deals with the 
risk contagion in the Chinese interbank market and then investigates the effects of risk sharing to the stability of the banking system. Section 5 concludes the paper.

\section{Literature Review}

A great deal of research, until recently, has recognized the importance of systemic risk in banking system. However, there is no consensus on an accepted definition of financial systemic risk. More recently Schweitzer et al. [3] explain that systemic risk can be generally described as the risk where a failing agent causes the failure of other agents. This definition differs from other notions of risk. For example, Embrechts et al. [4] treat the default of individual agents as an extreme event. They calculate the probability with the exclusion of the interaction among economic agents. In this sense, Tasca et al. [5] provide a lower bound for systemic risk. Billo et al. [6] define systemic risk as the probability of correlated defaults among financial institutions, even just in a short time, which in turn trigger a widespread liquidity shortage and loss of confidence in the financial system as a whole. Zheng et al. [7] address this definition as any set of circumstances that threatens the stability of the financial system, which may potentially spur financial crisis.

There are three primary approaches of measuring systemic risk: simulation method, network analysis, and matrix method. The first common method is simulation method. It measures the change of assets and liabilities of banks in each set period of time by determining specific distribution pattern of bank assets termly and includes KMV and credit metrics model. Angelini et al. [8] analyze the systemic risk of Italian interbank payment system with simulation method. Câmara et al. [9] estimate the implied probability of default from stock and options in the US by using KMV. In Galos and Soramaki's [10] study, an isolated, sudden, and unexpected failure of a bank can generate a widespread of consequences in alternative pan-European large-value payment system designs. They think in the risk of a particular systemic event, a sudden and unexpected failure of a bank where contagion is contained to the payment system, that is, which can be rather low. Yet, the simulation method does not apply to the interbank market in developing countries.

Another important method is the network approach, which analyzes the interaction between banks by building a credit network of banks with certain specification. Müller [11] employs network analysis to calculate risk contagion of banking system. In a related paper by Boss et al. [12], the network structure of the Austrian interbank market is of great concern, and the vertex between individual banks is linearly related to their contagion impact. Minoiu and Reyes [13] also demonstrate the global banking based on the network analysis. Unfortunately, the network approach is only valid when there is one or more center on the interbank market.

The third method is matrix analysis. Matrix method, averting from the data limitation, measures the risk contagion with risk exposure. Meng et al. [14] investigate the systemic risk of the US housing market at the state level based on the Random Matrix Theory. Upper and Worms
[2] estimate a matrix of bilateral credit relationships for the German banking system. Similarly, Mistrulli [15] observe risk contagion within the Italian interbank market by using the same method. These works all find that the breakdown of a single bank can lead to contagion.

Based on the above-mentioned three methods, many contributions have devoted to prove the existence of risk sharing. In a work by Campos [16], the risk sharing can generate feedback between the reallocation of wealth and the aggregate size of a shock. Similarly, Ortigueira and Siassi [17] reveal that intrahousehold risk sharing behavior exerts fairly large quantitative effects on all the margins detected. Ladley [18] indicates that interbank lending boosts stability through risk sharing or provides a channel to spread failure. These papers suggest that risk contagions coexist with risk sharing in the interbank market. Accordingly, risk sharing may support banking system stability.

Contagion and risk sharing in the interbank networks have been a hot research subject, but few are related to China. We herein select 16 representative commercial banks to detect contagion and risk sharing behavior in the Chinese interbank market. Taking no account of foreign and domestic nonbank transactions data, we build a risk exposure matrix of the Chinese interbank market by using the maximizing entropy method and then construct the network structure of the Chinese interbank market. After this, to quantify the changes of interbank market networks in an efficient way, we consider the mutual information of links between two successive networks. To better observe the dynamics of risk contagion, especially the changing behavior after the financial crisis, we simulate the risk contagion of the interbank market from 2005 to 2013. Besides we also discuss the stability of interbank market from risk sharing with a unique data set in 2013.

\section{The Model}

3.1. Interbank Matrix. Related studies have valuable insights into the matrix approach $[2,19]$. We use matrix analysis in the interbank market by following these studies. Suppose that there are $N$ banks in the interbank market, and their lending relationships can be represented by the following $N \times N$ matrix:

$$
\mathbf{X}=\left[\begin{array}{ccccc}
x_{11} & \cdots & x_{1 j} & \cdots & x_{1 N} \\
\vdots & \ddots & \vdots & \ddots & \vdots \\
x_{i 1} & \cdots & x_{i j} & \cdots & x_{i N} \\
\vdots & \ddots & \vdots & \ddots & \vdots \\
x_{N 1} & \cdots & x_{N j} & \cdots & x_{N N}
\end{array}\right]
$$

where $x_{i j}$ is the exposure of bank $i$ vis-à-vis bank $j$. The sum of each row and column, respectively, is total assets of bank $i$ on other banks and total liabilities of bank $j$ on other banks in the interbank market. Though there is no directly observed 
bilateral exposures information $x_{i j}$, each bank's interbank annual assets and liabilities are acquirable. Consider

$$
\begin{aligned}
& a_{i}=\sum_{j} x_{i j}, \\
& l_{j}=\sum_{i} x_{i j} .
\end{aligned}
$$

However, we cannot calculate all elements of matrix $\mathbf{X}$ only according to (2) and still have $N^{2}-2 N$ unknown elements. In order to estimate the bilateral exposures, we first use the information entropy.

Information entropy represents the statistics of the probability distribution state of random events in the whole system. The smaller the entropy value is, the lower the randomness of the events is. It is easier to predict which event will occur in the system. Assuming that an event exhibit two scenarios: the occurrence probability $p_{1}$ of scenario $\mathrm{A}$ is 1 and probability $p_{2}$ of scenario $\mathrm{B}$ is 0 . The consequence of this event will be up to the expression $H=-\sum_{i=1}^{n} p_{i} \ln p_{i}$ of entropy $\left(p_{i}\right.$ is the probability that event $i$ occurred). For two different events $X$ and $Y$, the probability matrix $(X, Y)$ joint entropy is defined as follows:

$$
H(x, y)=-\sum_{j} \sum_{i} p_{i j} \ln p_{i j},
$$

where $p_{i j}$ is the joint probability of $(X, Y)$. Thus matrix $\mathbf{X}$ information entropy is $-\sum_{j} \sum_{i} x_{i j} \ln x_{i j}$. To simplify the problem of maximum entropy of the distribution of interbank exposures, we normalize the interbank assets and liabilities to unity as suggested by Wells [20] (i.e., $\sum_{i} a_{i}=\sum_{j} l_{j}=1$ ) and calculate the key elements by the solution of the following linear programming:

$$
\begin{array}{ll}
\min & \sum_{j} \sum_{i} x_{i j} \ln x_{i j} \\
\text { s.t. } & a_{i}=\sum_{j} x_{i j}, \\
& l_{j}=\sum_{i} x_{i j}, \\
& x_{i j} \geq 0 .
\end{array}
$$

The Lagrangian function to this problem is given by

$$
\begin{aligned}
L(x, \lambda, \mu)= & \sum_{i=1} \sum_{j=1} x_{i j} \ln \left(x_{i j}\right)-\sum_{i=1} \lambda_{i}\left(\sum_{j=1} x_{i j}-a_{i}\right) \\
& -\sum_{j=1} \mu_{j}\left(\sum_{i=1} x_{i j}-l_{j}\right),
\end{aligned}
$$

and according to the first-order conditions the solution is given by

$$
x_{i j}=e^{\left(\lambda_{i}+\mu_{j}-1\right)}=e^{\left(\lambda_{i}-1 / 2\right)} e^{\left(\mu_{j}-1 / 2\right)} .
$$

We substitute (6) into the adding-up constraints of (4) and obtain the following equations:

$$
\begin{aligned}
e^{\lambda_{i}-1 / 2} \sum_{j=1} e^{\mu_{j}-1 / 2} & =a_{i}, \\
e^{\mu_{j}-1 / 2} \sum_{i=1} e^{\lambda_{i}-1 / 2} & =l_{j} .
\end{aligned}
$$

Because of the normalization (i.e., $\sum_{i} a_{i}=\sum_{j} l_{j}=1$ ), based on (6), we obtain the expression

$$
\sum_{i=1} \sum_{j=1} x_{i j}=\sum_{i=1} e^{\left(\lambda_{i}-1 / 2\right)} \sum_{j=1} e^{\left(\mu_{j}-1 / 2\right)}=1 .
$$

By combining (8) with (7), we acquire the formulas

$$
\begin{aligned}
e^{\left(\lambda_{i}-1 / 2\right)} & =\sum_{i=1} e^{\left(\lambda_{i}-1 / 2\right)} a_{i}, \\
e^{\left(\mu_{j}-1 / 2\right)} & =\sum_{j=1} e^{\left(\mu_{j}-1 / 2\right)} l_{j} .
\end{aligned}
$$

By substituting (9) into the solution (6), we obtain the result of (4):

$$
x_{i j}=a_{i} l_{j} \sum_{i=1} e^{\left(\lambda_{i}-1 / 2\right)} \sum_{j=1} e^{\left(\mu_{j}-1 / 2\right)}=a_{i} l_{j} .
$$

In accordance with the fact that banks cannot lend to themselves, the main diagonal elements must be zero. A new matrix $\mathbf{X}^{0}$ is set to enhance accuracy of the assumption and satisfy

$$
x_{i j}^{0}= \begin{cases}0, & \forall i=j, \\ x_{i j}, & \text { otherwise. }\end{cases}
$$

The problem does not necessarily disappear as the number of banks increases if interbank lending or borrowing is relatively concentrated. This means that we have to minimize the entropy of $\mathbf{X}^{0}$ with respect to a matrix $\mathbf{X}[2]$ :

$$
\begin{array}{ll}
\min & \sum_{i=1}^{N} \sum_{j=1}^{N} x_{i j} \ln \left(\frac{x_{i j}}{x_{i j}^{0}}\right) \\
\text { s.t. } & a_{i}=\sum_{j} x_{i j} \\
& l_{j}=\sum_{i} x_{i j}, \\
& x_{i j} \geq 0 .
\end{array}
$$

Consequently, we assume that $x_{i j}=0$, if and only if $x_{i j}^{0}=$ 0 , and $\ln (0 / 0) \equiv 0$.

3.2. The Network Structure of the Chinese Interbank Market. In this paper we secure matrix $\mathbf{X}$ of bilateral exposures by programming. $x_{i j}$ is the element of $\mathbf{X}$ which represents the exposure of bank $i$ vis- $\grave{a}$-vis bank $j$. But what we 
TABLE 1: 16 banks and respective symbols.

\begin{tabular}{lc}
\hline Bank & Symbol \\
\hline Agricultural Bank of China & ABC \\
Bank of Beijing & BOB \\
Band of China & BOC \\
Bank of Communications & BOCOM \\
Bank of Nanjing & BON \\
Bank of Ningbo & NBCB \\
China Construction Bank & CCB \\
China CITIC Bank & CNCB \\
China Everbright Bank & CEB \\
China Industrial Bank & CIB \\
China Merchants Bank & CMB \\
China Minsheng Banking & CMBC \\
Huaxia Bank & HXB \\
Industrial \& Commercial Bank of China & ICBC \\
Shanghai Pudong Development Bank & SPDB \\
Shengzhen Development Bank & SDB \\
\hline
\end{tabular}

present here is a complete network structure which is clearly inconsistent with the facts. When the lending ratio between two banks is less than a predetermined threshold value $c$, the edges between two banks are not contained in the network structure. In addition, we suppose $c=0.001$, and $\mathbf{Y}$ is the amended matrix.

If the matrix is multiplied by the total liabilities and then divided by the bank $i$ 's interbank liabilities, we can obtain the matrix $\mathbf{Z}$, which is a matrix of interbank debt ratio. $z_{i j}$ is the ratio between the asset of bank $j$ held by bank $i$ and the total amount of interbank liabilities of bank $j$.

\section{Empirical Researches}

4.1. Data. We focus on the representative banks of the Chinese interbank market, that is, 4 state-owned commercial banks and 12 joint-stock commercial banks by considering the difficulty of getting access to the data and these banks carry on most transactions in the Chinese interbank market. The empirical analysis is based on the annual reports of each bank from 2005 to 2013. In order to improve the precision of results, we only consider the lending relationships among domestic banks. Table 1 presents the name of primary Chinese banks in the control sample, where each symbol represents the bank in the empirical process. Figure 1 shows the size of total lending (the sum of each bank's interbank lending) in the Chinese interbank market, which has been growing quickly from 2007 to 2012 . For observing the specific connecting way in the Chinese interbank market network, we demonstrate the network structure of 2013 in the scenario of $c=0.001$ (Figure 2) as a sample.

4.2. The Mutual Information of Links. In order to investigate the change of links from year to year, we use the mutual information of links computed between two successive interbank market networks as suggested by Song et al. [21]. We consider

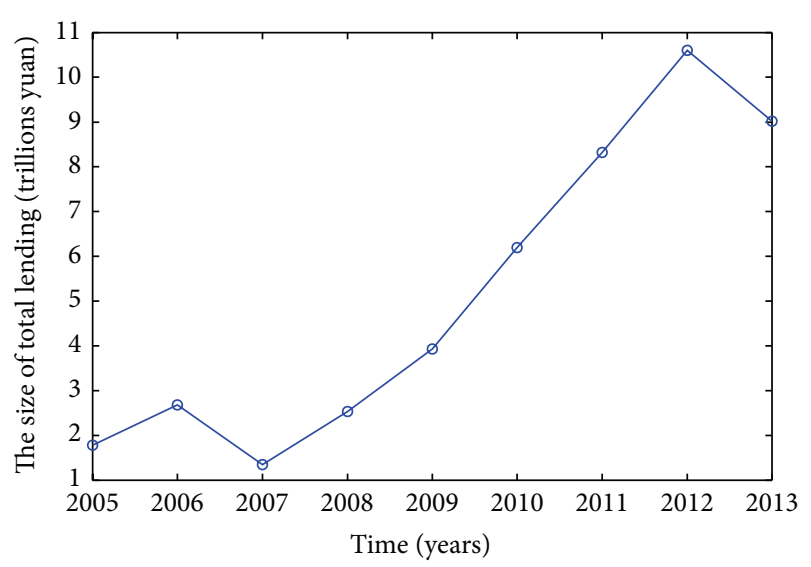

FIGURE 1: The size of interbank lending market.

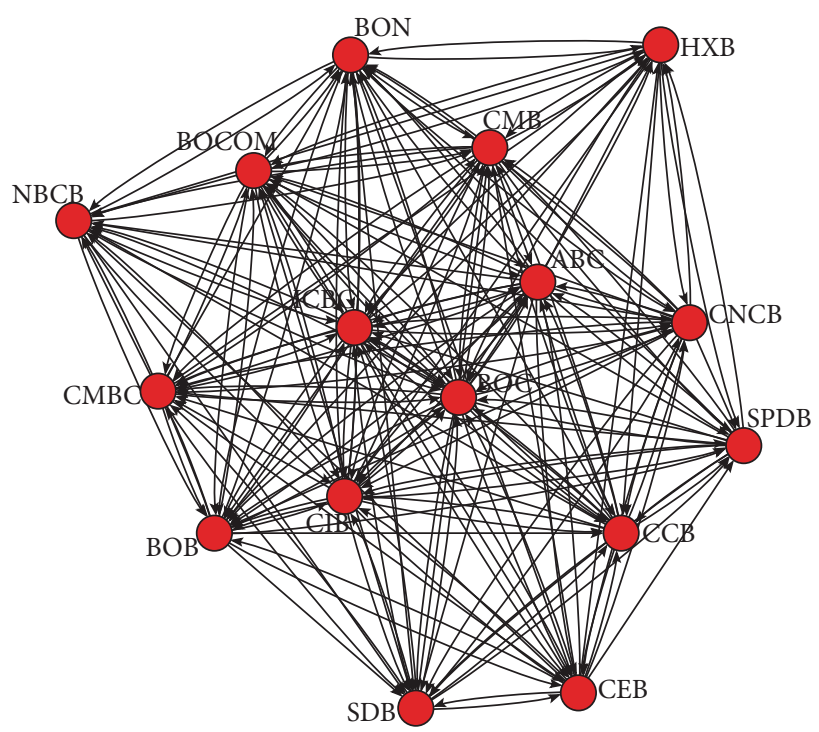

FIGURE 2: The network structure of the Chinese interbank market in 2013.

two networks that have the same vertices but have different links. We denote $N$ as the number of vertices and $n_{1}\left(n_{2}\right)$ as the number of links in the first (second) network. Following Song et al. [21], we use a binary random variable $x(y)$ to represent if two vertices are linked in the first (second) network. The value of $x(y)$ is 1 if two vertices are linked in the first (second) network; otherwise it is 0 . We denote $p_{1}(1)$ $\left(p_{2}(1)\right)$ as the probability that a randomly selected pair of vertices is linked in the first (second) network. Based on the above definitions, we obtain the following expressions:

$$
\begin{aligned}
& p_{1}(1)=\frac{n_{1}}{\left(N^{2}-N\right)}, \\
& p_{1}(0)=1-p_{1}(1), \\
& p_{2}(1)=\frac{n_{2}}{\left(N^{2}-N\right)}, \\
& p_{2}(0)=1-p_{2}(1) .
\end{aligned}
$$




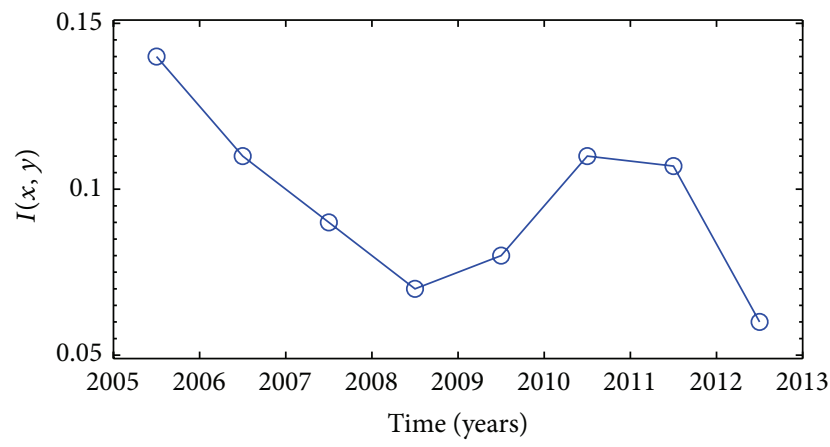

FIGURE 3: Mutual information of links between a network of the Chinese interbank market estimated at year $t$ and the network estimated at the year $t+1$.

Different from the undirected networks investigated in Song et al. [21], the network of the Chinese interbank market are directed networks, so the calculation of $p_{1}$ and $p_{2}$ is not multiplied by 2 . The calculation of the joined probability $p(x, y)$ of the two variables $x$ and $y$ is determined as follows:

$$
\begin{aligned}
& p(1,1)=\frac{n_{1,2}}{\left(N^{2}-N\right)}, \\
& p(1,0)=\frac{\left(n_{1}-n_{1,2}\right)}{\left(N^{2}-N\right)}, \\
& p(0,1)=\frac{\left(n_{2}-n_{1,2}\right)}{\left(N^{2}-N\right)}, \\
& p(0,0)=1-p(1,1)-p(1,0)-p(0,1),
\end{aligned}
$$

where $n_{1,2}$ is the number of the same links which are present in both networks. The mutual information of variables $x$ and $y$ is computed as follows:

$$
I(x, y)=\sum_{x=0,1} \sum_{y=0,1} p(x, y) \log \frac{p(x, y)}{p_{1}(x) p_{2}(y)} .
$$

In order to observe the changes of tightness between banks, we give the figure of degree observed in the networks of the Chinese interbank market (Figure 4). The degree is the sum of out-degree and in-degree of each bank node.

Figure 3 shows the mutual information between two successive networks of the Chinese interbank market. From the figure, we notice that each value of mutual information is lower than 0.15, which means the links in the Chinese interbank market have great changes year by year. Figure 4 shows the degree of each bank observed in the networks of the Chinese interbank market. We can know that the links between banks become tighter and tighter from 2005 to 2013 . Evidently, the degree of $\mathrm{ABC}$ is higher than other banks in 2005 and 2006, which implies that ABC plays an important role in the network of the Chinese interbank market in these two years. In the aftermath of that, the same thing arises in respect of the other two representative Chinese commercial banks (BOC and ICBC). We will discuss in the following parts whether these three banks will become the source of risk.

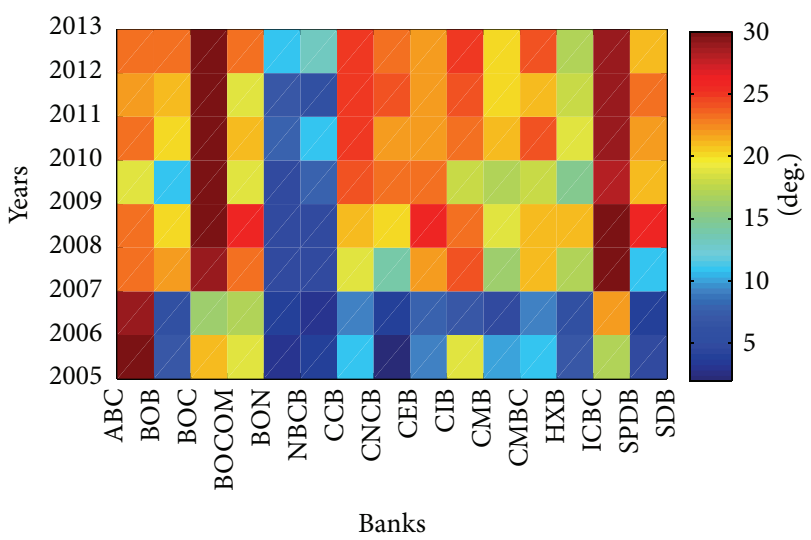

FIGURE 4: Color code representation of the time evolution of the degree of each banks observed in the networks of the Chinese interbank market computed by using a 1-year evaluation time period.

4.3. The Simulation of Risk Contagion. We estimate the scope for contagion by letting banks go bankrupt one at a time in the network of the Chinese interbank market and measure the number of failing banks owing to their direct or indirect exposure to the first failing bank. In our simulation, a bank's failure will cause the loss of its correspondent banks, and we define the loss rate as $\theta . C_{i}$ is the so-called core capital of bank $i$; the bank failures occur if $C_{i}<0$. We also assume that the loss rate $\theta$ remains fixed during the period of contagion. And it is necessary to point out that there is no safety net and support from third party.

In our study, $y_{i j}$ is bank $i$ 's gross exposure to bank $j$; the failure of bank $j$ triggers the failure of bank $i$ if $\theta y_{i j}>C_{i}$; otherwise risk contagion suspends. For example, if bank $i$ fails because of its exposure to bank $j$, bank $k$ will fail if its exposure of banks $j$ and $i$ multiplied by the loss rate exceeds its capital; that is, if $\theta\left(y_{k i}+y_{k j}\right)>C_{k}$, otherwise risk contagion suspends. This line of argument also applies to higher orders. The failure of a single bank can potentially give rise to a whole chain of succeeding failures (the "domino" effect).

Pursuant to the simulation of individual bank failures, which may cause numerous breakdowns of other banks at different loss rates, we aim to observe the specific banks which may represent the potential source of risk contagion. The results reveal that only $\mathrm{BOC}, \mathrm{ICBC}$, and $\mathrm{ABC}$ 's failures may lead to systemic risk in the network of the Chinese interbank market. And, herein, we demonstrate the results referring to the three special banks' failures. Tables 2, 3, and 4 report the loss rate, the year when the loss induces systemic risk, and banks which collapse because of the risk contagion.

As revealed in the empirical results, the risk contagion in network of the Chinese interbank market is characterized as follows.

In general, the failures of small banks will not lead to systemic risk contagion. A single bank failing will not lead to other banks' fail so long as the loss rate is lower than 0.45. From 2007, "domino" effects through interbank risk exposures seem to be possible in the case that the loss ratio reaches 0.85 . However, the benchmarking loss rate could 
TABLE 2: BOC as the source of risk contagion.

\begin{tabular}{|c|c|c|c|c|c|c|}
\hline Time & Loss rate & 1st & 2nd & $3 r d$ & 4 th & 5 th \\
\hline 2008 & 0.95 & CIB, SPDB & HXB, SDB, CEB & $\begin{array}{c}\text { BOCOM, CMBC, } \\
\text { BOB, BON }\end{array}$ & $\mathrm{CMB}$ & None \\
\hline 2009 & 0.95 & $\mathrm{CNCB}, \mathrm{CEB}$ & HXB, NBCB & SDB & None & \\
\hline 2011 & 0.85 & BOB & CIB, CNCB, SPDB & $\begin{array}{c}\text { BOCOM, CMBC, } \\
\text { HXB, SDB, BON, } \\
\text { NBCB }\end{array}$ & $\mathrm{CMB}$ & None \\
\hline 2012 & 0.95 & CIB & $\begin{array}{c}\text { SPDB, CMBC, SDB, } \\
\text { CEB, NBCP }\end{array}$ & $\begin{array}{c}\text { CNCB, HXB, BOB, } \\
\text { BON }\end{array}$ & None & \\
\hline 2013 & 0.95 & BON, NBCB & BOB, SPDB & CEB, $\mathrm{HXB}$ & None & \\
\hline
\end{tabular}

Notes: The table presents the results of the risk contagion exercises for BOC, which are reported for five different years when may cause numerous breakdowns. The second column gives the loss rate that will lead to systemic risk. The third to the seventh columns give the failed banks in each round.

TABLE 3: ICBC as the source of risk contagion.

\begin{tabular}{ccccccc}
\hline Time & Loss rate & 1st & 2nd & 3rd & 4th & 5th \\
\hline 2007 & 0.95 & $\begin{array}{c}\text { CIB, HXB, CEB, } \\
\text { BOB }\end{array}$ & CMB & None & & \\
\hline 2008 & 0.85 & CIB & SPDB, CEB & BOCOM, HXB, SDB & BOB & None \\
\hline 2009 & 0.95 & SPDB, CEB & HXB, SDB, NBCB & CIB & CNCB, CMBC & BOB \\
\hline 2011 & 0.99 & BOB & $\begin{array}{c}\text { CIB, CNCB, } \\
\text { SPDB }\end{array}$ & $\begin{array}{c}\text { BOC, CMBC, HXB, } \\
\text { CEB, BON, NBCB }\end{array}$ & $\begin{array}{c}\text { BOCOM, CMB, } \\
\text { SDB }\end{array}$ & None \\
\hline
\end{tabular}

Notes: The table presents the results of the risk contagion exercises for ICBC, which are reported for four different years when may cause numerous breakdowns. The second column gives the loss rate that will lead to systemic risk. The third to the eighth columns give the failed banks in each round.

TABLE 4: ABC as the source of risk contagion.

\begin{tabular}{|c|c|c|c|c|c|}
\hline Time & Loss rate & 1st & 2nd & 3 rd & 4th \\
\hline 2005 & 0.75 & CIB, SDB, CEB, SPDB & COCOM & $\mathrm{HXB}, \mathrm{SDB}$ & None \\
\hline 2006 & 0.65 & CIB, SDB, CEB, BOB & BOCOM, CMBC & HXB & None \\
\hline
\end{tabular}

be just 0.65 in 2005 and 2006, which may signify that the Chinese interbank market is more liable to triggering risk contagion in that period.

The danger of risk contagion is concentrated on a limited number of relatively large banks, for example, BOC, ICBC, and ABC. In 2005 and 2006, the failures of ABC most easily lead to risk contagion. Since then, the other two representative Chinese commercial banks, BOC and ICBC, may also trigger risk contagion in the Chinese banking system. However, until recent years, BOC and ICBC are more prone to triggering systemic risk for their rapidly increased size of capital and lending. In addition, these banks are just consistent with the banks which have higher degrees expressed in Figure 4 . The possibility of risk contagion challenges the policy making. Particularly, regulatory authorities should focus on the problems of these two banks and strengthen the prudential regulation on them.

As revealed in Table 2, two joint-stock Chinese banks, CIB and SPDB, are the most vulnerable banks in 2013. It is further confirmed that the regulator intervention comes at the crucial time to force banks to increase the amount of capital they hold, such as enlarging core capital ratio or decreasing the size of lending.
Nevertheless, the possibility of risk contagion is relatively low in the Chinese interbank market. The failures of banks will not trigger risk contagion except several large banks in the case that the loss ratio is higher than 0.85 . Moreover, we neglect a safety net and third party bailout in our simulations which may overestimate the effect of risk contagion.

At long last, the scale of interbank lending grows rapidly from 2007 which facilitates the liquidity but also amplifies the risk of danger. The key to maintain the stability of the system is to identify the risk contagion and promote effective regulatory policies to guarantee against the initial contagion shock.

4.4. The Simulation of Risk Sharing. Ladley [18] finds that for smaller shocks interbank lending relationships can reduce the financial contagion effects through risk sharing. In this paper, we examine the stabilization of the network of the Chinese interbank market through risk sharing, with the selection of a specific data set in 2013. By assuming that each bank would remain self-reliant to the point of bankruptcy, we further test the severity of shocks with the precise scale of loss.

Let $S$ be the scale of loss, if $S>C_{j}$; bank $j$ will collapse when under the pressures of shock, and simultaneously the 
TABLE 5: The process of banks facing collapse under different loss-scales.

\begin{tabular}{|c|c|c|c|c|}
\hline Losses-scale & $0.2 s$ & $0.3 s$ & $0.4 s$ & $0.5 s$ \\
\hline $\mathrm{BOC}$ & $\mathrm{BON}$ & $\mathrm{BON}$ & $\mathrm{BON}$ & BON, BOB, NBCB, SPDB \\
\hline ICBC & None & BON & BON & $\mathrm{BON}$ \\
\hline $\mathrm{ABC}$ & $\mathrm{BON}$ & $\mathrm{BON}$ & $\mathrm{BON}$ & $\mathrm{BON}, \mathrm{BOB}, \mathrm{NBCB}$ \\
\hline $\mathrm{CCB}$ & None & $\mathrm{BON}$ & $\mathrm{BON}$ & $\mathrm{BON}, \mathrm{BOB}$ \\
\hline BOCOM & $\mathrm{BON}$ & $\mathrm{BON}$ & $\mathrm{BON}$ & BON, BOB, NBCB, SPDB \\
\hline CMB & BON & BON & $\mathrm{BON}, \mathrm{BOB}$ & BON, BOB, NBCB, SPDB \\
\hline CIB & BON & BON & $\mathrm{BON}, \mathrm{BOB}$ & BON, BOB, NBCB, SPDB \\
\hline $\mathrm{CNCB}$ & $\mathrm{BON}$ & $\mathrm{BON}$ & $\mathrm{BON}, \mathrm{BOB}$ & BON, BOB, NBCB, SPDB \\
\hline SPDB & $\mathrm{BON}$ & $\mathrm{BON}$ & $\mathrm{BON}, \mathrm{BOB}, \mathrm{NBCB}$ & BON, BOB, NBCB \\
\hline СMBC & $\mathrm{BON}$ & $\mathrm{BON}$ & BON, BOB & BON, BOB, NBCB, SPDB \\
\hline HXB & $\mathrm{BON}$ & $\mathrm{BON}$ & $\mathrm{BON}, \mathrm{BOB}$ & BON, BOB, NBCB, SPDB \\
\hline SDB & $\mathrm{BON}$ & $\mathrm{BON}$ & $\mathrm{BON}, \mathrm{BOB}, \mathrm{NBCB}$ & BON, BOB, NBCB, SPDB \\
\hline CEB & BON & BON & $\mathrm{BON}, \mathrm{BOB}, \mathrm{NBCB}$ & BON, BOB, NBCB, SPDB \\
\hline BOB & BON & $\mathrm{BON}$ & BON, NBCB & BON, NBCB, SPDB \\
\hline $\mathrm{BON}$ & None & None & $\mathrm{BOB}, \mathrm{NBCB}$ & $\mathrm{BOB}, \mathrm{NBCB}, \mathrm{SPDB}$ \\
\hline NBCB & $\mathrm{BON}$ & $\mathrm{BON}$ & BON, BOB & BON, BOB, SPDB \\
\hline
\end{tabular}

remaining losses $\left(S-C_{j}\right)$ are shared across its creditor banks. $z_{i j}$ is the ratio of the asset of bank $j$ held by bank $i$ to the total amount of interbank liabilities of bank $j$. Therefore, a fraction of the losses which should be shared by creditor bank $i$ is $z_{i j}\left(S-C_{j}\right)$. Similarly, if $C_{i}<z_{i j}\left(S-C_{j}\right)$, the remaining losses are shared across creditor banks of bank $i$. Since bank $j$ cannot provide assistance in the next round, we suppose that $S 1$ is the remaining losses. In order to improve the accuracy, $S 1$ is calibrated to $S^{*}=S 1 /\left(1-x_{j i}\right)$ to eliminate the deviation caused by bank $j$, where there is a complete absence of self reliance. The losses which should be shared by bank $k$ are $S_{k}=z_{i k}\left(S-C_{i}\right)+\left(z_{i j}\left(S-C_{i}\right)-C_{j}\right)^{*} z_{j k}$, if bank $k$ is the common creditor bank of both banks $i$ and $j$. The cycle continues until all the losses are shared.

We use banks' total core capital $s$ as a reference and, respectively, simulate the situations of each bank under lossscales of $0.2 s, 0.3 s, 0.4 s$, and $0.5 s$. We further observe the number of banks, which are required to provide the total core capital in the brink of collapse. If the loss-scale is more than $0.5 s$, most banks will face the threat of collapse. Therefore, we only simulate the situations that the loss-scale is less than $0.5 s$.

Table 5 shows the empirical results in 2013. In our simulation, only fewer banks will face failures if all banks offer assistance to their associated banks initiatively. The first bank facing collapse is always the BON, which means the capital adequacy ratio of $\mathrm{BON}$ is too low to eliminate collateral damage caused by its associated banks.

However, the results also indicate that large banks' losses are more likely to be shared than small banks when they are subject to the same losses, because the large banks own larger core capital. So large banks can absorb part of the loss to reduce the pressure of risk sharing and then their failures are more likely to lead to risk contagion. Other banks should provide assistance to share the losses in order to maintain the stability of the banking system. The loss of banks that provide assistance to others is smaller than that of banks without providing assistance to others if $\theta y_{i j}>z_{i j}\left(S-C_{i}\right)$. Consequently, it is important to provide financial assistance initiatively for each bank.

In the process of risk sharing, the most vulnerable banks are three joint-stock banks, namely, BOB, BON, and NBCB. Therefore, the results in Table 5 resemble that of the easiest failing banks in 2013 reported in Table 2 which sheds light on the necessity to raise the capital adequacy ratio of those three banks.

\section{Discussions and Conclusions}

The financial crisis has rekindled interest in risk contagion in the interbank market. Lending risk in the interbank market may lead to "domino" effects, which means that the impact of failure of an initial bank can be transmitted to other banks through debt creditor relationships. In this paper, we estimate the network structure of the Chinese interbank market according to information of balance sheet. We investigate the overall changes of the Chinese interbank market network structures by using mutual information of link cooccurrence in networks with the same number of elements. Then we simulate the possibility of risk contagion in the Chinese interbank market from 2005 to 2013 and test the antirisk ability of the Chinese interbank market from the perspective of risk sharing.

We find that the links between banks become tighter and tighter in recent years, and the bank with a high "degree" easily leads to risk contagion, though the "domino" effects through interbank risk exposures are not significant. When the scale of the loss is underneath $0.4 s$, the Chinese banking system secures a considerable stabilization via mutual assistance to share risks.

Despite the fact that the danger of risk contagion is normally confined to a limited number of relatively large banks, bank failures remain a possibility affecting a sizeable 
part of the banking system. Therefore, the regulator should launch a broad investigation of banks which could trigger risk contagion. Firstly, the regulator needs to propose specific significant banks evaluation criteria for primary banks. We suggest that it is essential to refer to banks asset position and the size of the capital as the main indexes of evaluation. Secondly, it is significant to limit the exposures of banks to individual debtors and coordinate the banks lending relationships to increase the ability to resist risks. Finally, the regulator should draw up the measures to deal with the accident that a bank does fail. Besides, all banks also should do something to maintain the stability of the banking system. For example, other banks should work on the risk sharing initiatively when a counterpart bank is under attack.

We only simulate the situation of one bank under attack, through which domino effects arise. In reality, usually several banks are commonly shocked at the same time, where the domino effects would present a far more complex behavior than that in our simulation. In the future we could take this circumstance into account and simulate these far more complicated processes of contagion and risk sharing as well.

\section{Conflict of Interests}

The authors declare that there is no conflict of interests regarding the publication of this paper.

\section{Acknowledgments}

The research is supported by the National Natural Science Foundation of China under Grants nos. 71373072, 71501066, and 71521061, the Specialized Research Fund for the Doctoral Program of Higher Education under Grant no. 20130161110031, the China Scholarship Council under Grant no. 201506135022, the Social Science Foundation of Hunan Province of China under Grant no. 13YBA068, and the Natural Science Foundation of Hunan Province of China under Grant no. 2015JJ3045.

\section{References}

[1] F. Allen and D. Gale, "Financial contagion," Journal of Political Economy, vol. 108, no. 1, pp. 1-33, 2000.

[2] C. Upper and A. Worms, "Estimating bilateral exposures in the German interbank market: is there a danger of contagion?" European Economic Review, vol. 48, no. 4, pp. 827-849, 2004.

[3] F. Schweitzer, G. Fagiolo, and D. Sornette, "Economic networks: the new challenges," Science, vol. 325, no. 5939, pp. 422-425, 2009.

[4] P. Embrechts, C. Kluppelberg, and T. Mikosch, "Fluctuations of upper order statistics," in Modelling Extremal Events: For Insurance and Finance, pp. 183-199, Springer, Berlin, Germany, 2011.

[5] P. Tasca, P. Mavrodiev, and F. Schweitzer, "Quantifying the impact of leveraging and diversification on systemic risk," Journal of Financial Stability, vol. 15, pp. 43-52, 2014.

[6] M. Billo, M. Getmansky, A. W. Lo, and L. Pelizzon, "Econometric measures of connectedness and systemic risk in the finance and insurance sectors," Journal of Financial Economics, vol. 104, no. 3, pp. 535-559, 2012.

[7] Z. Zheng, B. Podobnik, L. Feng, and B. Li, "Changes in crosscorrelations as an indicator for systemic risk," Scientific Reports, vol. 2, article 888, 2012.

[8] P. Angelini, G. Maresca, and D. Russo, "Systemic risk in the netting system," Journal of Banking \& Finance, vol. 20, no. 5, pp. 853-868, 1996.

[9] A. Câmara, I. Popova, and B. Simkins, "A comparative study of the probability of default for global financial firms," Journal of Banking \& Finance, vol. 36, no. 3, pp. 717-732, 2012.

[10] P. Galos and K. Soramaki, "Systemic risk in alternative payment system designs," European Central Bank Working Paper Series 508, European Central Bank, Frankfurt, Germany, 2005.

[11] J. Müller, "Interbank credit lines as a channel of contagion," Journal of Financial Services Research, vol. 29, no. 1, pp. 37-60, 2006.

[12] M. Boss, M. Summe, and S. Thurner, "Contagion flow through banking network," in Computational Science-ICCS 2004: 4th International Conference, Kraków, Poland, June 6-9, 2004, Proceedings, Part III, vol. 3038 of Lecture Notes in Computer Science, pp. 1070-1077, Springer, Berlin, Germany, 2004.

[13] C. Minoiu and J. A. Reyes, "A network analysis of global banking: 1978-2010," Journal of Financial Stability, vol. 9, no. 2, pp. 168-184, 2013.

[14] H. Meng, W.-J. Xie, Z.-Q. Jiang, B. Podobnik, W.-X. Zhou, and H. E. Stanley, "Systemic risk and spatiotemporal dynamics of the US housing market," Scientific Reports, vol. 4, article 3655, 7 pages, 2013.

[15] P. E. Mistrulli, "Assessing financial contagion in the interbank market: maximum entropy versus observed interbank lending patterns," Journal of Banking \& Finance, vol. 35, no. 5, pp. 11141127, 2011.

[16] R. G. Campos, "Risk-sharing and crises. Global games of regime change with endogenous wealth," Journal of Economic Theory, vol. 148, no. 4, pp. 1624-1658, 2013.

[17] S. Ortigueira and N. Siassi, "How important is intra-household risk sharing for savings and labor supply?" Journal of Monetary Economics, vol. 60, no. 6, pp. 650-666, 2013.

[18] D. Ladley, "Contagion and risk-sharing on the inter-bank market," Journal of Economic Dynamics \& Control, vol. 37, no. 7, pp. 1384-1400, 2013.

[19] D. Hans and N. Gregory, "Interbank exposures: an empirical examination of contagion risk in the Belgian banking system," International Journal of Central Banking, vol. 3, no. 2, pp. 123172, 2007.

[20] S. Wells, "Financial interlinkages in the United Kingdom's interbank market and the risk of contagion," Bank of England Working Paper 230, Social Science Research Network, 2004.

[21] D.-M. Song, M. Tumminello, W.-X. Zhou, and R. N. Mantegna, "Evolution of worldwide stock markets, correlation structure, and correlation-based graphs," Physical Review E, vol. 84, no. 2, Article ID 026108, 2011. 


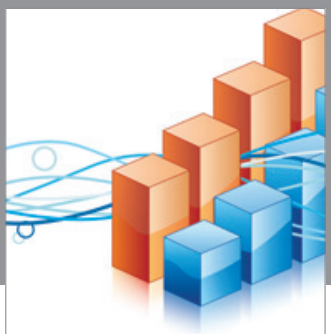

Advances in

Operations Research

vatem alat4

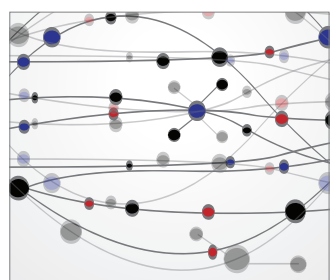

\section{The Scientific} World Journal
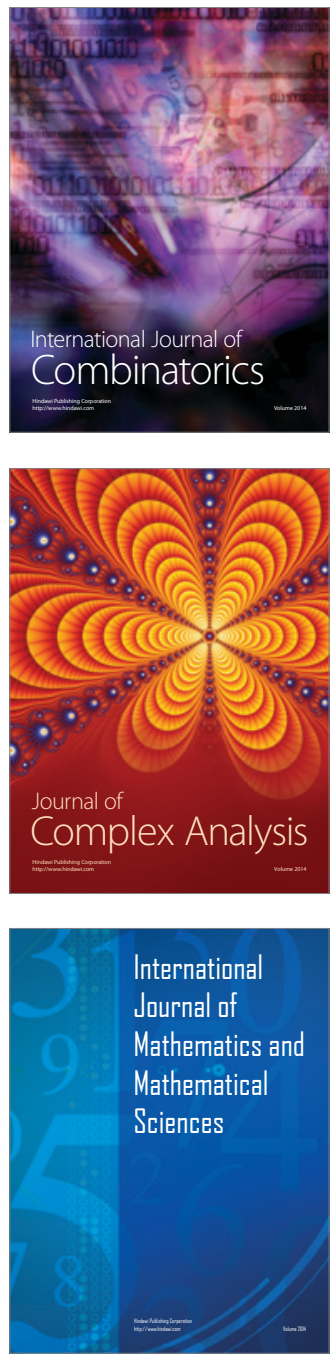
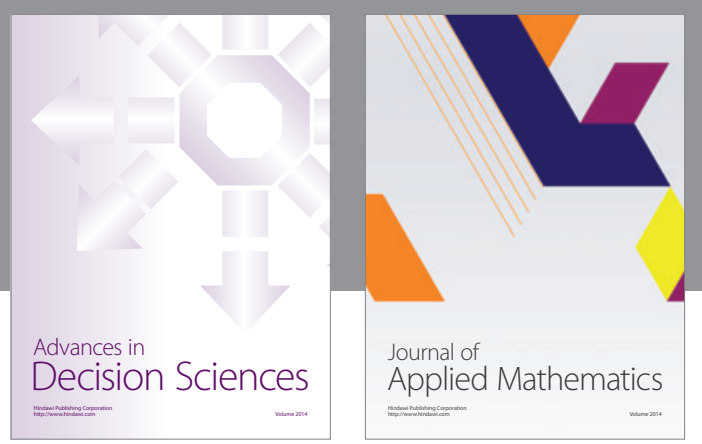

Algebra

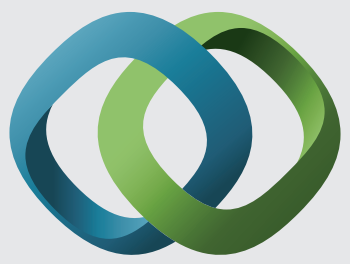

\section{Hindawi}

Submit your manuscripts at

http://www.hindawi.com
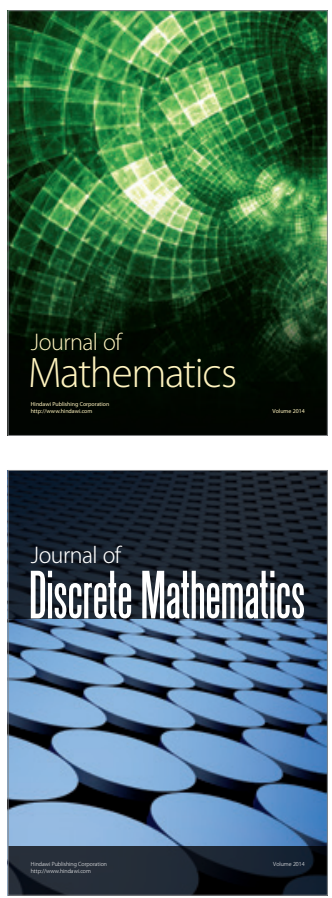

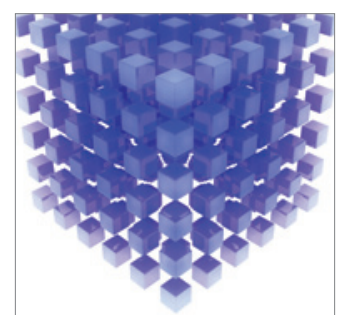

Mathematical Problems in Engineering
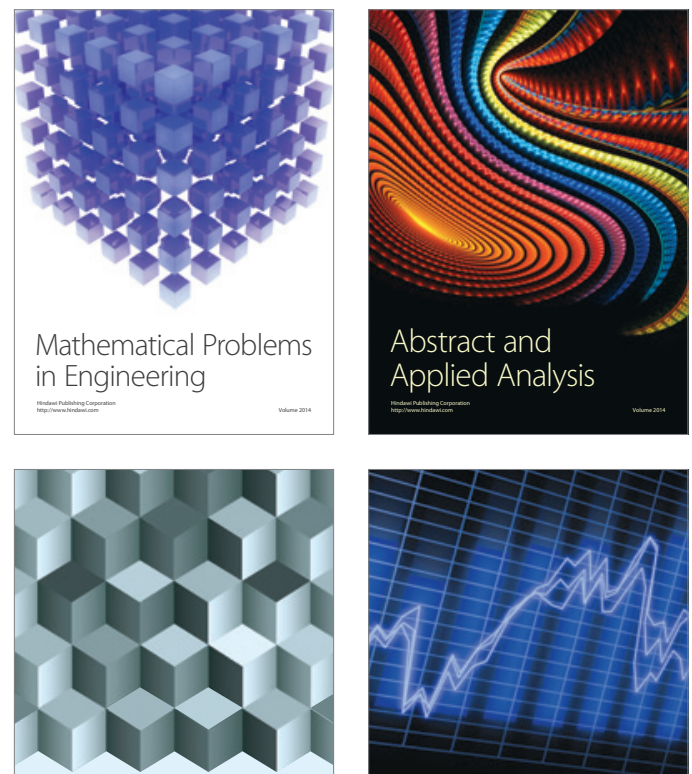

Journal of

Function Spaces

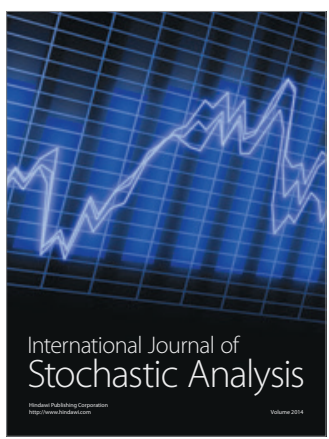

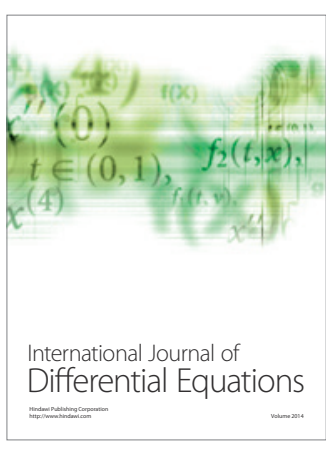
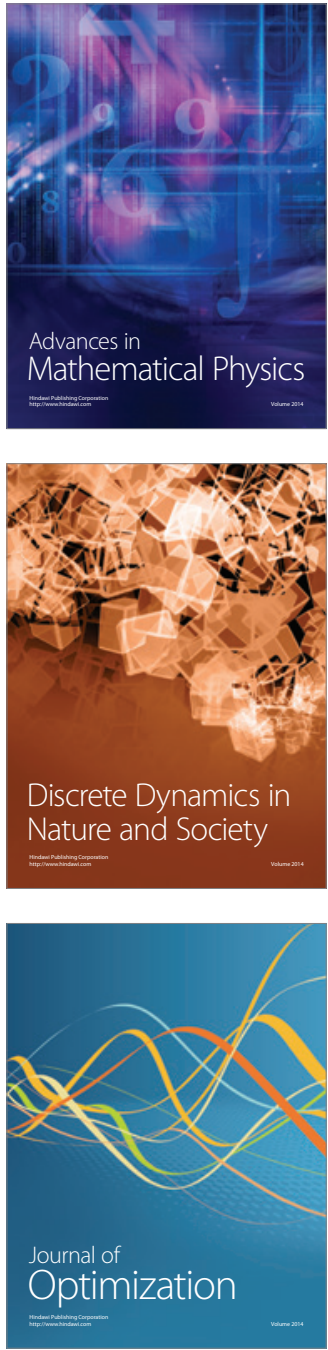